УДК 330

\author{
Пенькова Инесса Вячеславовна
}

\title{
ИНСТИТУЦИОНАЛЬНЫЕ ЛОВУШКИ ЦИФРОВОЙ ЭКОНОМИКИ
}

В статье поставлена ијель выявить основные институциональные ловуики, возникаюиие в прочессе формирования цифровой экономики. В рамках исследования поставлены и решень задачи относительно раскрытия понятия «институциональная ловушка» применительно к циифровой экономике, определения основных институциональных ловуиек на современном этапе развития информационно-экономических отношений и выявления предположительных путей их преодоления. На основании теоретического анализа таких сложсивиихся неэффективных институтов, как неурегулированная интеллектуальная собственность, морально изноченный производственный фонд, неотработанные нормы воспроизводства творческой личности, сделан вывод, что они являются основным источником формирования институциональных ловуиек. Пути преодоления ловуиек автор видит в практической реализачии Программы цифровой экономики России с главным вектором на фориирование «цифрового человека», обладающей компетенциями творческой реализачии личностного потенциала в мобильно меняюиейся среде цифровой экономики с одновременным активно модернизируемьм техническим ее оснащением.

Ключевые слова: институциональные ловуики, инновации, творческая личность, интеллектуальная собственность, иифровая экономика.

\section{Inessa Penkova \\ INSTITUTIONAL TRAPS OF DIGITAL ECONOMY}

The article aims at identifying the core institutional traps arising in the process of forming a digital economy. Within the research tasks were set and resolved regarding the concept of "institutional trap» in relation to the digital economy, identifying the main institutional traps at the current stage of developing information and economic relations and identifying hypothetical ways to overcome them. Based on the theoretical analysis of the existing inefficient institutions such as unresolved intellectual property, obsolete production fund, purely regulated norms of a creative person reproduction, it has been concluded that they are the foremost source of institutional traps. The author sees the ways to overcome the traps in the practical implementation of the Digital Economy Program of Russia with the main vector directed to the formation of $a$ «digital human» possessing the competencies of creative realization of personal potential in the rapidly changing digital economic environment followed by its technical equipment actively modernized. economy

Key words: institutional traps, innovation, creative personality, intellectual property, digital

Bведение /Introduction. Переход к информационному типу хозяйственной системы, характерный для многих стран, в том числе и для России, представляется движением «через неопределенность, без этого не может быть качественного преобразования. В период неопределенности разгорается борьба между старым и новым, т. е. между консервативными хозяйствующими субъектами и их политическими сторонниками, с одной стороны, и инновационными хозяйствующими субъектами и их политическими сторонниками - с другой. Так разгорается бифукационная борьба» [1, с. 112], которая разделяется на множество ветвей и превращается в полифукацию [1, c. 113]. В рамках такого подхода одним из проблематичных аспектов представляется выявление информационно-экономических взаимосвязей и отношений, формирующих, с одной стороны, институциональные ловушки, преодоление которых, с другой стороны, становится основой инновационной составляющей и направленности развития и реформ [2, с. 19-33].

Именно о дуализме современных процессов цифровизации социально-экономического пространства и пойдет речь в предлагаемой статье. 
В рамках заявленной проблемы ставится целью выявление путей преодоления институциональных ловушек. Достижение такой цели потребовало решения ряда задач:

- раскрыть понятие «институциональная ловушка» применительно к цифровой экономике;

- $\quad$ выявить основные институциональные ловушки на современном этапе развития информационно-экономических отношений и предложить пути их преодоления.

Maтериалы и методы / Materials and methods. При проведении исследования применялись методы ретроспективного анализа относительно тенденций развития институциональных процессов в условиях становления цифровой, или так называемой информационной, экономики. При научном анализе использовались результаты изысканий, представленные в монографиях, научных и методических публикациях, аналитических докладах, статистических справочниках, и материалы законодательных актов и правоустанавливающих документов.

Pезультаты и обсуждение / Results and discussion. В начале исследования уточним, что целесообразно воспользоваться определением «институциональных ловушек», данным В. Полтеровичем [3, с. 5], в соответствии с которым они являются неэффективными устойчивыми институтами, настолько «вжившимися» в систему, что даже при внешнем воздействии после возмущения система возвращается в прежнее состояние.

Итак, предпримем попытку выявить такие ловушки в период активного формирования цифровой экономики в России, когда трансформирующиеся информационно-экономические отношения предполагают решение ряда цивилизационно и исторически сформировавшихся норм.

Во-первых, обратим внимание на проблематику института интеллектуальной собственности, который обусловливает ряд выгод для предпринимателя, государства и общества. Так, Н. Гаврилова [4, с. 33] группирует выгоды предпринимателя в три крупных блока: конкурентные преимущества, финансовые выгоды и выгоды от использования интеллектуальной собственности в качестве вклада в уставный капитал. Выгоды для государства включают дополнительные налоговые платежи от повышения объемов продаж контрактной продукции, привлечение новых инвестиций в отрасли, внедряющие новейшие научно-технические достижения, что обеспечивает рост ВВП. Для общества выгодность состоит в возможности для потребителей приобретать товары по более низким ценам, в верификации источников научно-технической информации при удовлетворении потребностей населения в образовании и в просветительских целях.

Однако, согласно оценкам исследователей, например, в США 20-25 \% патентов не используется в хозяйственной практике, для государственных патентов эта доля составляет $96 \%$. Менее двух третей всех первоначально запланированных нововведений проходит стадию исследований и разработок, половина из прошедших этот этап доходит до стадии рыночного сбыта, лишь 0,5-3,5\% первоначальных идей способны себя окупить, и только 10-30\% идей могут быть запатентованным изобретением. Промышленному предприятию необходимо в среднем 58 идей, чтобы обеспечить себе успех на рынке с помощью одного изделия [5, с. 65].

С одной стороны, используя данное И. Корниловой определение инновации как системного понятия, «с помощью которого идея, изобретение в первый раз превращается в коммерческую реальность» $[6$, с. 12], можно исследовать особенности рыночных, коммерческих трансакций с учетом возникающих информационных и транзакционных издержек.

С другой стороны, если рассматривать инновацию как «специфический инструмент предприимчивости, действие, придающее ресурсам новые возможности создания богатствау [7, с. 39], то можно считать, что «инновация превращается в главное средство выживания в условиях острой конкурентной борьбы» [6, с. 50]. Аналогичной точки зрения придерживаются Б. Адамов, Л. Винарик и А. Щедрин, полагая, что «...важнейшим из ресурсов, требуемых для успешной конкуренции, служат знания, значимые для каждого бизнеса в ключевых областях компетентности. Ядром конкурентных преимуществ служит система ключевых областей компетентности» [8, с. 3]. 
Функциональное значение инновации Й. Шумпетер [9, с. 21] определяет как «непостоянное проведение новых комбинаций», что заведомо формирует институциональную ловушку. И тут для подтверждения нашего мнения обратимся к утверждению П. Друкера, что определяющим фактором востребованности инновации становится не ее научность или степень новизны, а успех на рынке [7, с. 4].

Повышение роли потребителя на рынке в условиях постиндустриального этапа развития определяет первичность рассмотрения полезности научно-технической продукции. Внутренним качеством полезности научно-технической продукции является ее рыночная новизна. Она определяется как мера отличия научно-технической продукции по уровню удовлетворения потребностей потребителя от уже существующих видов продукции и услуг. Рыночная новизна опирается на научно-техническую, идентификация уровня которой возможна на основе выяснения места последней в иерархии по видам инноваций и которая закладывает методологию определения исходного потенциала ее конкурентоспособности. По уровню научно-технической новизны В. Кудашов выделяет следующие виды инноваций $[10$, с. 9-10]: революционные, радикальные, принципиальные, а также инновации, направленные на усовершенствование используемых технологий.

Тем не менее в ходе реформ, бессистемной приватизации и коммерциализации научно-технической сферы были раздроблены единые научно-технические структуры, что оказало разрушающее воздействие на материально-производственные возможности промышленности и материально-техническую базу науки. В частности, произошла почти полная смена профиля опытно-экспериментальных производств (ОЭП). Так, за годы рыночных реформ в России более 60 \% ОЭП и испытательных баз вышли из состава гражданских машиностроительных НИИ и перепрофилированы, а оставшиеся, в том числе и уникальные, используются в коммерческих целях $[11$, c. 12]; это, в свою очередь, нарушило целостность симбиоза научно-технических организаций и привело к ослаблению научно-технической базы производства, что создало устойчивую институциональную ловушку морально изношенного производственного потенциала.

Изложенные положения приобретают тем большее значение, если принять во внимание тот факт, что информационно-экономические отношения могут предопределить технологические критерии конкурентоспособности страны на мировой арене, среди которых Ю. Яковец рассматривает [12, с. 4-9] такие как:

- социально-экономическая политика, обеспечивающая технологические потребности производства;

- целесообразность формирования шестого технологического уклада и более активное внедрение и применение инноваций;

- формирование и развитие научного, изобретательского и исследовательского потенциалов;

- обеспечение социально-экономической эффективности принципиально новой техники с учетом фактора времени;

- возможность обеспечения ресурсами приоритетных направлений науки, техники и критических технологий, принимая во внимание ожидаемые темпы роста ВВП и источники инноваций и инвестиций.

Данные критерии могут способствовать развитию следующих приоритетных направлений науки и техники:

- междисциплинарных фундаментальных исследований и долгосрочных прогнозов;

- биомедицины и биотехнологии на основе генной инженерии, имеющих ключевое значение для укрепления здоровья человека;

- новейших информационных технологий и систем, которые могут предоставить возможность более эффективного использования отечественного потенциала экономики и социокультурной сферы и уверенного позиционирования страны в мировом сообществе; 
- энергосберегающих технологий и нетрадиционных энергоресурсов, приобретающих первостепенное значение в связи с сокращением доступных нефти, газа и угля;

- создания принципиально новых экологически чистых материалов, требующих минимальной обработки и затрат;

- $\quad$ разработки систем машин и производственных технологий нового поколения, которые предназначены для замены устаревающих производственных возможностей;

- авиакосмических технологий, новых средств транспорта и связи для обеспечения растущих темпов мобильности в различных сферах жизнедеятельности человека;

- оборонно-технических средств и систем обеспечения безопасности страны.

Чтобы избежать деградации научно-технической базы страны целесообразно предпринять ряд комплексных мер. В подтверждение такой позиции выступает и В. Кушлин, который, исследуя проблемы модернизации российской экономики, пишет: «Во-первых, более весомой могла бы быть роль федеральных целевых программ, причем не только собственно научно-технических; инновационное наполнение в той или иной степени должны иметь практически все приоритетные программы. Во-вторых, инновационную деятельность нужно налаживать по всем направлениям производственной деятельности... данное направление надо считать в сегодняшних условиях определяющим для перелома» $[13$, с. 8$]$. И в соответствии с мировыми тенденциями, в большинстве индустриальных стран подавляющая часть (50-80\%) всех затрат на НИОКР покрывается именно за счет средств корпораций и государственных инвестиций в инновации. По расчетам Э. фон Хиппеля, средняя стоимость единицы НИОКР для имитатора (субъъекта, имитирующего уже существующее нововведение) составляет $65 \%$ от уровня лидера, а средние затраты времени на освоение, соответственно, $-70 \%[14$, с. 15$]$.

Тем не менее сложно оспорить тот факт, что в интенсивности инновационного развития и в деле умножения богатства важную роль играет интеллектуальный капитал. Интеллектуальные способности человека, его знания и навыки следует отнести к особой форме капитала, которую можно охарактеризовать как интеллектуальный капитал.

Анализ интеллектуального капитала приводит к выводу о том, что, во-первых, он является неотъемлемым личным достоянием, т. е. собственностью; во-вторых, обеспечивает своему обладателю будущий доход, компенсируя отказ от части текущего потребления; в-третьих, требует для своего развития значительных общественных и личных затрат; в-четвертых, имеет свойство накапливаться, т. е. представляет собой определенный запас [1, с. 77]. По мнению А. Чухно, интеллектуальный капитал предоставляет возможность экономить технику, высвобождает финансы, благоприятствует росту прибыльности экономической деятельности [15, с. 40$]$.

Рассмотрение интеллектуального капитала, по мнению О. Бервено, целесообразно вести в двух направлениях, определяющих сферу его функционирования [1, с. 76]:

1) временной порядок, который предоставляет основу для исследования социальной памяти;

2) пространственный порядок, когда интеллектуальный капитал меняет ландшафт человеческих отношений, их связи и принципы, открывает качественно новые возможности человеческого развития, партнерства и сетевых организаций, формирования мировых информационных сетей, повышения уровня социального доверия в обществе.

Интеллектуальный капитал становится господствующим видом капитала, а интеллектуальная деятельность - основным видом человеческой деятельности и составляет основную часть совокупного общественного труда, что подтверждает предсказания Дж. Гэлбрейта о создании в будущем империи интеллекта. О. Беревено полагает, что «накопление интеллектуального богатства... замещает все традиционные формы богатства» [1, с. 80-81]. Аналогичное мнение высказывает Ю. Гава $[16$, с. 35], полагая, что уровень образования и образованности, отношение граждан к культурным, духовным и интеллектуальным ценностям выступают первоисточником высокого жизненного уровня. 
Следует вспомнить, что на интеллект оказывают влияние наследуемость, общая среда, различающаяся среда, случайные средовые воздействия и гендерный фактор. Такая предпосылка дает основания для серьезных исследований социальной сферы, а особенно условий социальной защищенности и гарантий: системы здравоохранения (бесплатной или страховой медицины), качества образования, уровня зарплаты, пенсий и льгот для различных социальных групп и т. п. По нашему мнению, именно эти социальные факторы и условия способны повлиять на наследуемость и гендерный ингредиент общества.

Важным элементом интеллектуального капитала представляется нравственная составляющая. Соглашаясь с В. Гойло, отметим, что нравственный капитал заключается «в народной честности, народной предприимчивости... в живом и ревностном участии к общему благу, в привычке не полагаться на внешнюю помощь, не искать ее в силах, лежащих извне, но и находить в самом себе, в привычке к самостоятельности» [17, с. 78].

Уровень нравственности, в свою очередь, обусловливает информационную культуру общения, взаимоотношений и духовность. Так, например, «имея достаточный уровень информационной культуры, современный экономист эффективно организовывает свое рабочее место, увеличивает возможности по расширению сбыта продукции и услуг, обеспечивая тем самым дополнительные доходы предприятия» [18, с. 19]. Более того, экспорт интеллекта в виде информационной продукции, технологий, и в том числе и оффшорного или аутсорсингового программирования, становится источником высокого дохода и глобальной цифровизации.

Современный период социально-экономического развития характеризуется переходом отношений экономических агентов в новую информационно-экономическую плоскость, что, в свою очередь, обусловлено формированием и становлением информационной экономики. Этот процесс затрагивает и коренным образом реформирует все сферы и уровни экономики.

Здесь следует согласиться с мнением современных ученых, которые считают, что для экономики характерны три этапа социально-экономических реформ:

- $\quad$ первый этап реформ - преобразование базовых институтов рыночной конкуренции и восстановление макроэкономической и политической стабильности;

- в второй этап - начало формирования экономических институтов, характерных для современного общества и более точно ориентированных на российскую специфику. Главное внимание уделяется созданию базовых институтов рыночной экономики: гражданского, налогового, трудового и земельного кодексов, пенсионного законодательства, снижение административных барьеров к предпринимательской деятельности и др.;

- третий этап - реализация стратегии социально-экономического прорыва в условиях современного цифрового общества. Успех или неуспех дальнейшего развития зависит от политики власти. На этом этапе ключевыми становятся так называемые проблемы «третьего поколения» - вопросы развития человека, инвестиций в человеческий капитал, а также задачи укрепления и совершенствования политических институтов. Основным вопросами, требующими решения, представляются не макроэкономические проблемы и не совершенствование экономических институтов, так как они уже в основном сформированы, а конкурентное преимущество современной высокоразвитой страны связано с творческой личностью, институтами, ее формирующими, и факторами, непосредственно обеспечивающими жизнедеятельность человека.

О. Белорус и Д. Лукьяненко определяют в качестве источника стоимости продукта интеллектуальный потенциал работника, а не его психофизические усилия $[19$, с. 47]. Аналогичной точки зрения придерживаются В. Иноземцев и О. Антипина. Они полагают, что «утверждение новых ценностей, в центре которых - человек с его стремлением к совершенствованию» [20, с. 43], представляется отличительной чертой цифровой или информационной экономики. А. Чухно называет человека «мерой и главным фактором прогресса» [15, с. 18]. 
Подтверждением данного положения может стать анализ характерных особенностей информационной экономики, базовыми из которых являются творческий человек, повышение роли интеллектуального работника и «работника знаний», знания и информация как средства производства, продукт и средство обмена.

Таким образом, одним из наиболее важных и проблематичных аспектов становления цифровой экономики становится преодоление институциональных ловушек в направлении формирования творческой образованной личности. Тем не менее условия протекания и углубления этого процесса различны в разных странах. Целесообразно определить общие основополагающие факторы создания творческой личности и проанализировать их наличие и состояние в экономике России для выявления перспектив полноправного участия нашей страны в общемировых трансформациях на пути к информационной экономике.

За основу классификации следует принять преломленный в плоскость анализа условий формирования творческой личности социогуманистический подход к становлению информационной экономики, цель которого - системное изучение комплекса факторов:

- экономических и технологических (производственная деятельность, инвестиции, доходы);

- социальных (демографическая ситуация, безработица, социальная защита, обеспеченность жильем, здравоохранение);

- духовно-интеллектуальных (образование, наука, культура).

Развитие и применение творческих способностей человека и его интеллектуального потенциала предполагает наличие широкой производственной сферы деятельности, выдвигающей требования технологических усовершенствований, и рост объемов производства. Особую актуальность этот процесс приобретает в условиях инновационных преобразований, базирующихся на достижениях НТП, открытии рыночных ниш специфических потребностей и обострении конкуренции. Однако не теряют ведущей роли и такие традиционные показатели, как ВВП, безработица, инвестиции и др.

Так как одним из наиболее весомых мотивирующих факторов роста интеллектуализации труда являются материальные стимулы и получение вознаграждения в соответствии с многообразными теориями мотивации, и материальные потребности перестают играть решающую роль только тогда, когда они удовлетворены, то достигать быстрых темпов роста «творческого труда» преждевременно.

На этапе развития цифровой экономики России целесообразно выработать сбалансированную программу, сочетающую трансформации рыночного характера с созданием и расширением объемов высокотехнологичного информационного производства и наращивания объемов производства в перечисленных сферах.

Особенно важно уделить внимание сфере образования и науки, по той причине, что именно здесь создаются, интерпретируются, накапливаются и трансформируются знания, которые являются неотъемлемой составляющей информационной экономики.

Творческий труд есть не что иное, как преломление накопленных знаний в зависимости от сферы применения, накопленного опыта и мастерства. Существенным базовым фактором, определяющим предпосылки «созревания» человека творческого труда и подлежащим анализу, является культурное и духовное здоровье нации. Этот аспект предопределяет психологические условия, влияющие на производительность труда человека, его моральный облик, общественный статус и мотивацию к эффективной производственной деятельности. Стратегический ресурс этой области значителен, и его интенсивное развитие требует существенных усилий государства и общества в целом. Эффективное функционирование этого сектора приводит к потребности приложения синергетических усилий для продолжительного постоянного целенаправленного участия каждого индивида в продуцировании и реализации социальных инноваций не только на уровне человека, общины или отдельной области, но и этноса, государства и международного сообщества. 
В свою очередь, этот процесс непосредственно и направленно с положительным вектором может влиять на генерирование ценной информации, построение конкурентоспособного инновационно-цифрового общества, повышение духовно-информационной мобильности личности и общества и на культурно-духовную преемственность поколений посредством накопления опыта, знаний и информации и оздоровления социально-гуманистических условий формирования и развития «творческого работника».

В заключение поиска выходов из «институциональных ловушек» на основе исследования условий и предпосылок формирования и развития человека творческого интеллектуального труда и «цифровой личности» можно сделать некоторые выводы.

Условия становления и воспитания человека творческого труда в период общемирового процесса перехода к информационной стадии формируются в России на фоне:

- пролонгированного научно-технологического развития производства и недостаточной доли инвестиций и расходов на образование и социальную сферу;

- относительно высокого процента бедного населения и низкой материальной мотивации труда (не учитывая психологических мотиваторов);

- интенсификации участия государства в процессе укрепления и оздоровления социально-гуманистической сферы общества, возрождения духовности и культуры нации.

Заключение / Conclusion. Для ускорения темпов и повышения эффективности процесса становления «цифровой экономики» и полноправного участия России в общемировом процессе информационно-экономических трансформаций путем преодоления «институциональных ловушек» целесообразными могут быть следующие меры:

- в экономической сфере: реализовывать стратегическую программу экономического роста с вектором на практическую цифровизацию, ориентированную на инновационный информационно-технологический тип производства, обеспечивая государственную поддержку наукоемких, высокотехнологических и энергосберегающих технологий в промышленности и сельском хозяйстве, необходимую конкуренцию субъектов производства для повышения конкурентоспособности на мировом рынке;

- в социальной сфере: обеспечивать со стороны государства достойный уровень социальной поддержки, не ограничивая прав и свобод личности, гарантируя получение качественного медицинского обслуживания и образования, в направлении формирования «цифрового человека», востребованность полученной профессии посредством создания адекватных рабочих мест;

- в культурной сфере: продолжать создавать условия развития интеллекта и культуры нации, возрождения духовности, опираясь на опыт поколений, накопленные знания и высокие технологии.

Таким образом, отметим, что нивелирование негативного воздействие сложившихся «институциональных ловушек» в условиях развивающихся информационно-экономических отношений имеет целью создание новой социально-хозяйственной атмосферы, предполагающей минимум бюрократии, снижение коррумпированности, четкую и понятную миссию субъектов хозяйствования, по возможности полный доступ к финансовой и другой информации, расширение полномочий при участии различных уровней персонала в принятии решений, большую степень свободы, ответственность при разумной отчетности и постоянное новаторство.

\section{ЛИТЕРАТУРА И ИНТЕРНЕТ-РЕСУРСЫ}

1. Бервено О. В. Интеллектуальный капитал: экономическое содержание и особенности формирования в транзитивном обществе: дис. ... канд. экон. наук. 08.01 .01 / О. В. Бервено; Харьковский национальный университет им. В. Н. Каразина. Харьков, 2002. С. 200. 
2. Сологубова Г. С. Составляющие цифровой трансформации: монография. М.: Юрайт, 2018. 141 с.

3. Полтерович В. М. Институциональные ловушки и экономические реформы. М.: Российская экономическая школа, 1998.37 с.

4. Гаврилова Н. Преимущества использования интеллектуальной собственности // Экономист. 2002. № 4. C. $32-35$.

5. Санто Б. Инновация как средство экономического развития. М.: Прогресс, 1990. $296 \mathrm{c}$

6. Корнилова И. Н. Становление рынка научно-технической продукции: дис. ... канд. экон. наук: 08.01.01. / И. Н. Корниова. Киев: Киевский ун-т им. Т. Шевченко, 1996. 209 с.

7. Druker P. Innovation and Entrepreneurship. N. Y.: Perennial Library, 1986. 277 p.

8. Приоритеты прорыва в информационную экономику / Б. И. Адамов, Л. С. Винарик, А. Н. Щедрин // Вісник економічної науки України. 2006. № 1(9). С. 3-6.

9. Shumpeter J. Business Cycles: A Historical and Statistical Analysis of the Capitalist Process. N. Y.: McGrow-Hill, 1939. 457 p.

10. Кудашов В. И. Научно-технические нововведения: организационно-экономический механизм управления в условиях перехода к рынку. Минск: Университетское, 1993. 232 с.

11. Гуржиев В. Факторы инновационной направленности инвестиций // Экономист. 2002. № 3. С. 11-12.

12. Яковец Ю. Стратегия научно-инновационного прорыва // Экономист. 2002. № 5. С. 3-11.

13. Кушлин В. Цель и факторы модернизации экономики // Экономист. 2001. № 8. С. 3-10.

14. Хиппель Э. Инновационная политика развитых капиталистических государств // Сб. тр. ВНИИ сист. исслед. М.: ВНИИ сист. исслед.,1990, - 84 с.

15. Чухно А. Новая экономическая политика (теоретико-методологические начала) // Экономика Украины. 2005. № 7. С. 15-22.

16. Гава Ю.В. Інтелектуальний капітал - стратегічний ресурс «постіндустріальної економіки» // Вісник економічної науки України. 2006. № 1(9). С. 35-38.

17. Гойло В. С. Современные буржуазные теории воспроизводства рабочей силы. М.: Наука, 1975. 357 с.

18. Коляда М. Г. Формирование информационной культуры будущих экономистов в процессе профессиональной подготовки: дис. ... канд. пед. наук / М. Г. Коляда. Донецк: Донецкий институт социального образования, 2003. 209 с.

19. Белорус О. Г., Лукьяненко Д. Г. и др. Глобальные трансформации и стратегии развития: монография. Киев: Орияне, 2000. 234 с.

20. Иноземцев В. Л., Антипина О. Н. Постэкономическая революция и глобальные проблемы человечества // Общественные науки и современность. 1998. № 4. С. 41-54.

\section{REFERENCES AND INTERNET RESOURCES}

1. Berveno O. V. Intellektual'nyj kapital: ekonomicheskoe soderzhanie i osobennosti formirovaniya $\mathrm{v}$ tranzitivnom obshchestve (Intellectual capital: economic content and features of formation in a transitive society): dis. ... kand. ekon. nauk: 08.01.01 / O. V. Berveno. Har'kov, Har'kovskij nacional'nyj universitet im. V. N. Karazina, 2002. S. 200.

2. Sologubova G. S. Sostavlyayushchie cifrovoj transformacii (Components of digital transformation): monografiya. M.: Yurajt, 2018. $141 \mathrm{~s}$.

3. Polterovich V. M. Institucional'nye lovushki i ekonomicheskie reform (Institutional traps and economic reforms). M.: Rossijskaya ekonomicheskaya shkola, 1998. $37 \mathrm{~s}$.

4. Gavrilova N. Preimushchestva ispol'zovaniya intellektual'noj sobstvennosti (The benefits of using intellectual property) // Ekonomist. 2002. № 4. S. 32-35.

5. Santo B. Innovaciya kak sredstvo ekonomicheskogo razvitiya. (Innovation as a means of economic development). M.: Progress, 1990. 296 s.

6. Kornilova I. N. Stanovlenie rynka nauchno-tekhnicheskoj produkcii (Formation of the scientific and technical products market): dis. ... kand. ekon. nauk: 08.01.01. / I. N. Korniova. Kiev: Kievskij universitet im. T. Shevchenko, 1996. $209 \mathrm{~s}$.

7. Druker P. Innovation and Entrepreneurship. N. Y.: Perennial Library, 1986. $277 \mathrm{s.}$

8. Prioritety proryva v informacionnuyu ekonomiku (Priorities for breakthroughs in the information economy)/ B. I. Adamov, L. S. Vinarik, A. N. Shchedrin // Visnik ekonomichnoï nauki Ukraïni. 2006. № 1(9). S. 3-6. 
9. Shumpeter J. Business Cycles: A Historical and Statistical Analysis of the Capitalist Process. N. Y.: McGrow-Hill, 1939. $457 \mathrm{~s}$.

10. Kudashov V. I. Nauchno-tekhnicheskie novovvedeniya: organizacionno-ekonomicheskij mekhanizm upravleniya $\mathrm{v}$ usloviyah perekhoda $\mathrm{k}$ rynku (Scientific and technical innovations: organizational and economic mechanism of management in the transition to a market). Minsk: Universitetskoe, 1993.232 s.

11. Gurzhiev V. Faktory innovacionnoj napravlennosti investicij (Factors of innovative investment orientation)// Ekonomist. 2002. № 3. S. 11-12.

12. Yakovec Yu. Strategiya nauchno-innovacionnogo proryva (Strategy scientific innovation breakthrough) // Ekonomist. 2002. № 5. S. 3-11.

13. Kushlin V. Cel' i faktory modernizacii ekonomiki (The purpose and factors of economic modernization) // Ekonomist. 2001. № 8. S. 3-10.

14. Hippel' E. Innovacionnaya politika razvityh kapitalisticheskih gosudarstv (Innovative policies of developed capitalist states). // Sb. tr. VNII sist. issled. M.: VNII sist. issled., 1990. $84 \mathrm{~s}$.

15. Chuhno A. Novaya ekonomicheskaya politika (teoretiko-metodologicheskie nachala) (New economic policy (theoretical and methodological principles)) // Ekonomika Ukraini. 2005. № 7. S. 15-22.

16. Gava Yu. V. Intelektual'nij kapital - strategichnij resurs «postindustrial'noï ekonomiki» (Intellectual capital is a strategic resource of the "post-industrial economy") // Visnik ekonomichnoï nauki Ukraïni. 2006. № 1(9). - S. 35-38.

17. Gojlo V. S. Sovremennye burzhuaznye teorii vosproizvodstva rabochej sily. (Modern bourgeois theories of labor reproduction). M.: Nauka, 1975. $357 \mathrm{~s}$.

18. Kolyada M. G. Formirovanie informacionnoj kul'tury budushchih ekonomistov v processe professional'noj podgotovki (Formation of information culture of future economists in the process of professional training): dis. ... kand. ped. nauk / M. G. Kolyada/ Doneck: Doneckij institut social'nogo obrazovaniya, 2003. 209 s.

19. Belorus O. G., Luk'yanenko D. G. i dr. Global'nye transformacii i strategii razvitiya (Global Transformations and Development Strategies): monografiya. Kiev: Oriyane, 2000. 234 s.

20. Inozemcev V. L., Antipina O. N. Postekonomicheskaya revolyuciya i global'nye problemy chelovechestva (Posteconomic revolution and global problems of mankind) // Obshchestvennye nauki i sovremennost'. 1998. № 4. S. 41-54.

\section{СВЕДЕНИЯ ОБ АВТОРЕ}

Пенькова Инесса Вячеславовна, доктор экономических наук, профессор, профессор кафедры бизнес-информатики, Северо-Кавказский федеральный университет, г. Ставрополь. E-mail: panacea_inessa@mail.ru

\section{INFORMATION ABOUT AUTHOR}

Inessa Penkova, Doctor of Economics, Professor, Professor of Business Informatics Department, North-Caucasus Federal University, Stavropol. E-mail: panacea_inessa@mail.ru 